\title{
Performance of Energy Consumption and Indoor Air Quality for the Fan coil System with Sensor Fault
}

\author{
Liangzhen Jiao ${ }^{1, \mathrm{a}}$, Shuai $\mathrm{He}^{1, \mathrm{~b}}$, Yunpeng $\mathrm{Hu}^{2, \mathrm{c},{ }^{*}}$, Jiayu Zhou ${ }^{1, \mathrm{~d}}$ \\ ${ }^{1}$ College of Urban Construction, Wuhan University of Science and Technology, Wuhan 430081, \\ China \\ ${ }^{2}$ Wuhan Business University, Wuhan 430056, China \\ a jiaoliangzhen@wust.edu.cn, ${ }^{b}$ heshuai7426@foxmail.com, ${ }^{\text {,.* }}$ Corresponding author: \\ YunpengHu@wbu.edu.cn, ${ }^{d}$ zhoujiayujs@163.com
}

\begin{abstract}
Keywords: Energy Consumption; Indoor Air Quality; Sensor; Fault; Fan coil system
Abstract. The fan coil systems are employed to create a satisfied built environment by some feedback controls. Sensor is one of the most important components in the whole system. Unfortunately, Due to the long term using, sensors fault would occur unavoidable. It is significant to reduce the energy consumption while seeking for higher system efficiency and a better indoor air quality. A fan coil system model was simulated by EnergyPlus and was used to investigate the certain effects on the sensor fault in the system. The key sensor, chilled water outlet temperature, was introduced different bias fault from $+2 \square$ to $-4 \square$. The results shows that positive deviations of chilled water outlet temperature sensor fault have a worse effect on energy consumption, chiller performance efficiency, and indoor thermal comfort than negative fault levels.
\end{abstract}

\section{Introduction}

Sensor is one of the most important parts in the air-condition system. However, sensor fault occurs easily and are found out hardly. Sensor fault would always cause a decrease in the system performance, an increase of the energy consumption, a worse indoor thermal comfort. Therefore, many fault detection, diagnosis (FDD) algorithm were employed to identify the erroneous sensor. FDD can accurately identify the source of the sensor fault and greatly reduce maintenance costs [1-5].

Some studies have shown that the sensor fault would greatly affect the energy consumption of air-condition system [6]. The sensor fault would cause an annual energy consumption increase up to $30 \%$ 50\% in an office building. A research on air handing unit (AHU) simulation figure out that the sensor fault of return air flow would cause a $14 \%$ energy consumption increase [7]. Also, in a variable volume air-condition system, the energy consumption growth would augment to $36.57 \%$ when blade opening sensor fault on the air terminal device occurred; $11.47 \%$ when supply air temperature sensor fault occurred; $21.15 \%$ when room air temperature sensor fault occurred [8]. The difference of total system energy consumption could augment to $21.84 \%$, when sensor fault occurred in a central air-condition cooling water system [9].

This paper employed EnergyPlus to simulate a real fan coil system under key sensor fault with different bias faults. The parameters, including efficiency, the energy consumption, and the indoor air quality, ware investigated by the comparison with different cases.

\section{Models}

A four-floor building located in Wuhan, China, was simulated by EnergyPlus to investigate the performance of energy consumption and indoor air quality.

Model description. There are 38 thermal zones with different types, such as classroom, office room, meeting room, training room, and laboratory, in this building. The simulation timestep is 2 minutes within the whole simulation period from June 1st to August 31st. Table 1 shows the detail simulation characteristics of the building model. 
Table 1 Simulation characteristics of the building model

\begin{tabular}{cc}
\hline Item & Content \\
\hline Air-condition area $\left[\mathrm{m}^{-2}\right]$ & $6683.3 \mathrm{~m}^{2}$ \\
Floor dimension $[\mathrm{m} \times \mathrm{m}]$ & 1 st floor: $80 \times 35$; Other floors: $63 \times 26.7$ \\
Floor height $[\mathrm{m}]$ & 1 st floor : 8; Other floors : 4.2 \\
Indoor air temperature setpoint $\left[{ }^{\circ} \mathrm{C}\right]$ & 26 \\
Fresh air flow rate $\left[\mathrm{m}^{3} /(\mathrm{h} \cdot\right.$ person$\left.)\right]$ & 30 \\
Occupancy density $\left[\mathrm{m}^{2} /\right.$ person $]$ & Classroom : 3; Office : 4; Others : 5 \\
Lighting load density $\left[\mathrm{W} / \mathrm{m}^{2}\right]$ & Classroom :12; Office : 11; Others : 15 \\
Air side system & FCU ( fan coil ) + fresh air \\
Water side system & Water-cooled chiller (rated power:402kW, rated COP: 3.2) \\
& Constant-speed chilled water pump (rated power:5.763kW) \\
& Variable-speed condensed water pump (rated power:3.67kW) \\
\hline
\end{tabular}

Senor fault mathematic description. Normally, the measured value of sensor can be described as

$$
t_{m}=t_{r}+\xi+\eta
$$

where $t_{m}$ is the measured value, $t_{r}$ is the real value, $\xi$ is the random error and $\eta$ is the fault, also known as the systematic error. The accurate measured value of all kinds of sensors, especially of the sensor with the set point in feedback control logic, is an important guarantee for the safe and reliable operation.

There are some feedback control logics in the fan coil system to ensure the whole fan coil system working rightly. When sensor faults occurred, automatic control system would adjust the system condition according to the sensor fault feedback value. Usually, the chilled water outlet temperature is the set point of the chilled water feedback control logic. It was assumed, for an instance, that the real chilled water outlet temperature is $6.5^{\circ} \mathrm{C}$, the setpoint of it is $7^{\circ} \mathrm{C}$, and the random error is zero while the systematic error is $+1^{\circ} \mathrm{C}$. From Eq. 1 , the measured value of chilled water outlet temperature is 7.5 ${ }^{\circ} \mathrm{C}$ so as it is greater than the set point and the chiller will not stop. The chiller will keep working until the real chilled water outlet temperature is below the is $6.0{ }^{\circ} \mathrm{C}$ which means that the measured value is below the set point. From the mathematics description, the positive systematic error will make the real chilled water outlet temperature below the set point. On the contrary, the negative systematic error will make the real chilled water outlet temperature high the set point.

\section{Results}

This paper simulated the different operation condition of chilled water outlet temperature sensor faults. The energy consumption of the system, the efficiency of the chiller, and the human thermal comfort evaluation index were investigated to the consequence results of the sensor fault. The fault range is from $+2^{\circ} \mathrm{C}$ to $-4^{\circ} \mathrm{C}$ with its corresponding real chilled water outlet temperature varying from $5^{\circ} \mathrm{C}$ to 11 ${ }^{\circ} \mathrm{C}$.

Energy consumption performance. Different bias faults of the chilled water outlet temperature sensor results in different changes on energy consumption of chiller as well as the whole fan coil 
system. Fig. 1 shows the changing percentage of energy consumption for the chiller and the whole system comparing to the standard operating condition with $7^{\circ} \mathrm{C}$ set point for chilled water outlet temperature.

Obviously, positive deviations of chilled water outlet temperature sensor fault had a bigger effect on energy consumption both of the chiller and the total than the negative fault level. The energy consumption increased with the increase of positive deviation and, on the contrary, decreased with the increase of negative deviation. The most energy-saving condition was that chilled water outlet temperature set as $10^{\circ} \mathrm{C}$ (bias value set as $-3^{\circ} \mathrm{C}$ ). It was more conductive to energy conservation, while real higher chilled water outlet temperature was set.

Chiller efficiency performance. Chilled water outlet temperature sensor faults would derive that the control system would increase or reduce the chilled water outlet temperature according to the feedback set point. In this process, the evaporation temperature of chiller also changed, as well as the chiller unit refrigerating capacity. Fig. 2 shows the detail COP distribution of different condition from Jul. 19 to Jul. 21. In the most of the time during simulation, chiller COP value was lower than the rated value.

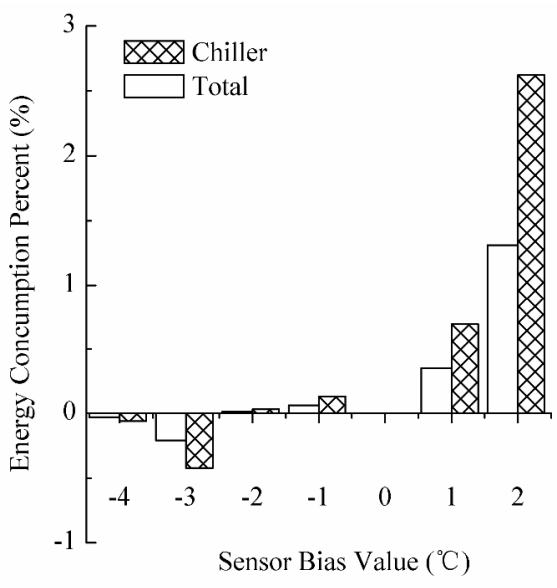

Figure 1 Energy consumption under different faults

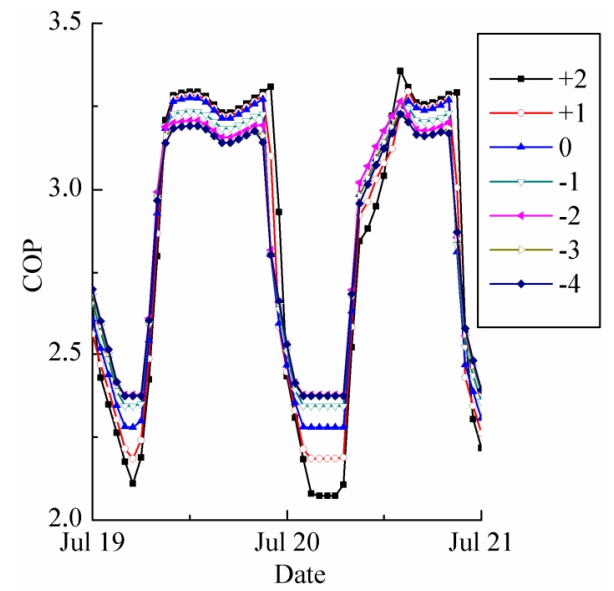

Figure 2 COP under different faults

Analyzing the average and median of the change for the chiller COP, it was shown that negative deviations were more conductive to improve the performance efficiency of the chiller than other conditions. When chilled water outlet temperature bias value set as $-4^{\circ} \mathrm{C}$ and $-2^{\circ} \mathrm{C}$, more than $63.8 \%$ of the whole simulation time, the chiller worked at a condition COP $>2.56$. When chilled water outlet temperature set as $9^{\circ} \mathrm{C}$, which means the bias fault is $-2^{\circ} \mathrm{C}$, the operation of the chiller efficiency was highest.

Indoor Thermal comfort. The Fanger PMV model and the indoor mean air temperature ware employed to study the indoor effects caused by different fault levels of chilled water outlet temperature sensor. 


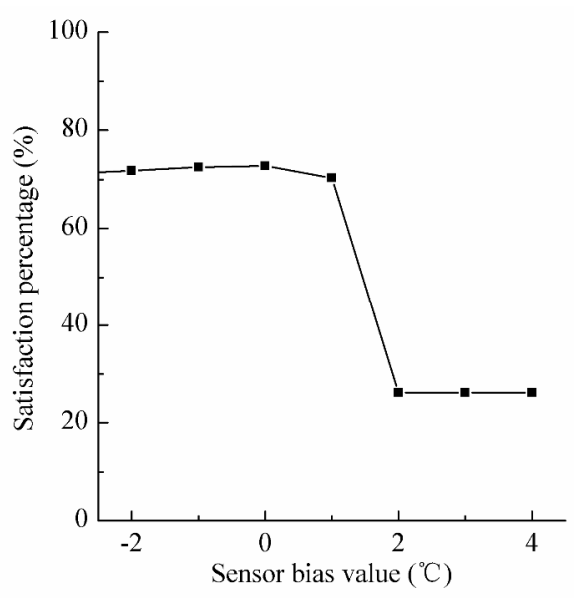

Figure 3 satisfaction percentage of PMV

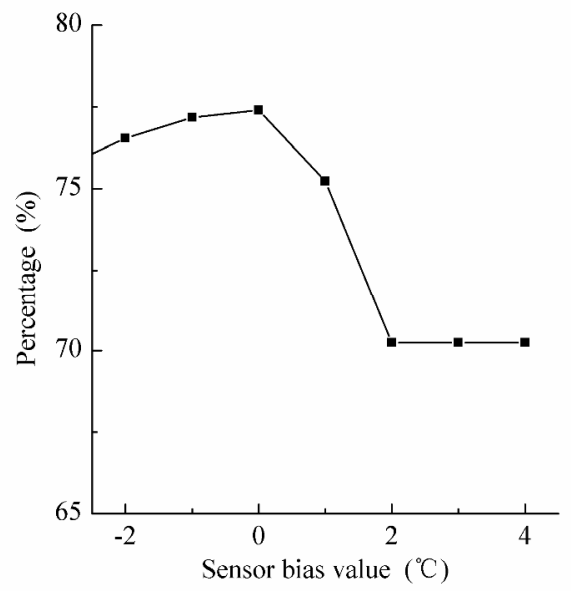

Figure 4 The time proportion percentage of indoor mean air temperature range from $25^{\circ} \mathrm{C}$ to 27

${ }^{\circ} \mathrm{C}$

Taking one of the classrooms as an example, Fig. 3 shows the satisfaction percentage of PMV which is the time proportion of PMV range from -1 to 1 under different bias value. Fig. 4 shows the time proportion percentage of indoor mean air temperature range from $25^{\circ} \mathrm{C}$ to $27^{\circ} \mathrm{C}$ under different bias value. When positive fault of chilled water outlet temperature sensor fault occurred, both the indoor thermal comfort and indoor mean air temperature are greatly reduced. However, while there are the negative fault levels, the influences became gently.

\section{Conclusion}

Due to the long term using, sensors fault would occur unavoidable. In this paper, a fan coil system of a real building was simulated to investigate the performance effects under sensor fault condition by EnergyPlus. The key sensor, chilled water outlet temperature, was introduced different bias fault from $+2^{\circ} \mathrm{C}$ to $-4^{\circ} \mathrm{C}$. The results shows that positive deviations of chilled water outlet temperature sensor fault have a worse effect on energy consumption, chiller performance efficiency, and indoor thermal comfort than negative deviations.

It is very important to ensure the health and normal measurement of the sensors, especially the sensors involved into the feedback control logic. With the development of intelligent buildings, online sensor fault detection and diagnosis (FDD) should be taken seriously. The real-time online FDD is essential to save building energy consumption, to maintain a good indoor air quality.

\section{Acknowledgements}

This work was financially supported by the Natural Science Foundation of Hubei Province of China (2016CFB472), Doctoral R\&D Foundation of Wuhan Business University of China (2016KB001), Scientific and Technological Innovation Foundation of Wuhan Business University of China (2016KC04), National Training Programs of Innovation and Entrepreneurship for Undergraduates of China (201710488016).

\section{References}

[1] S. Shi, G. Li, H. Chen, Y. Hu, X. Wang, Y. Guo, S. Sun. An efficient VRF system fault diagnosis strategy for refrigerant charge amount based on PCA and dual neural network model. Appl Therm Eng. Vol. 129 (2018), p. 1252-1262. 
[2] Y. Guo, G. Li, H. Chen, Y. Hu, L. Shen, H. Li, M. Hu, J. Li. Development of a virtual variable-speed compressor power sensor for variable refrigerant flow air conditioning system. Int J Refrig. Vol. 74 (2017), p. 73-85.

[3] G. Olivia, T.A. Christopher. In-use monitoring of buildings: An overview and classification of evaluation methods. Energ Buildings. Vol. 86 (2015), p. 176-189.

[4] Y. Hu, H. Chen, G. Li, H. Li, R. Xu, J. Li. In-use monitoring of buildings: An overview and classification of evaluation methods. Energ Buildings. Vol. 112 (2016), p. 270-278.

[5] W. Kim, J.E. Braun. Development and evaluation of virtual refrigerant mass flow sensors for fault detection and diagnostics. Int J Refrig. Vol. 63 (2016), p. 184-198.

[6] M.S. Kim, W.V. Payne, P.A. Domanski, S.H. Yoon, C.J.L. Hermes. Performance of a residential heat pump operating in the cooling mode with single faults imposed. Appl Therm Eng. Vol. 29 (2009), p. 770-778.

[7] S.W. Wang, F. Xiao. AHU sensor fault diagnosis using principal component analysis method. Energ Buildings. Vol. 36 (2004), p. 147-160.

[8] S.H. Lee, F.W.H. Yik. A study on the energy penalty of various air-side system faults in buildings. Energ Buildings. Vol. 42 (2010), p. 2-10.

[9] Z. Ma, S. Wang. Online fault detection and robust control of condenser cooling water systems in building central chiller plants. Energ Buildings, 2011, Vol. 43, p. 153-165. 